\title{
HARMS, Wolfgang, SCHILLING, Michael, Das illustrierte Flugblatt der frühen Neuzeit. Traditionen, Wirkungen, Kontexte
}

\section{Naïma Ghermani}

\section{OpenEdition}

\section{Journals}

Édition électronique

URL : http://journals.openedition.org/ifha/1832

DOI : 10.4000/ifha.1832

ISSN : 2198-8943

Éditeur

IFRA - Institut franco-allemand (sciences historiques et sociales)

Référence électronique

Naïma Ghermani, «HARMS, Wolfgang, SCHILLING, Michael, Das illustrierte Flugblatt der frühen Neuzeit Traditionen, Wirkungen, Kontexte », Revue de I'IFHA [En ligne], Date de recension, mis en ligne le 01 janvier 2009, consulté le 22 septembre 2020. URL : http://journals.openedition.org/ifha/1832 ; DOI : https://doi.org/10.4000/ifha.1832

Ce document a été généré automatiquement le 22 septembre 2020.

(CIFHA 


\title{
HARMS, Wolfgang, SCHILLING, Michael, Das illustrierte Flugblatt der frühen Neuzeit. Traditionen, Wirkungen, Kontexte
}

\author{
Naïma Ghermani
}

1 Véritable histoire d'un projet de recherche, ce recueil publié par W.H. et M.S. n'est pas le simple rassemblement d'articles consacrés à l'étude des feuilles volantes à l'époque moderne : c'est aussi la reconstitution d'une aventure intellectuelle d'un groupe de chercheurs réunis autour du professeur à l'Université de Hambourg, W.H. qui eut le privilège, dès les années 1970, de découvrir l'incroyable fond de feuilles volantes de la bibliothèque de Wolfenbüttel et ses richesses inespérées pour l'analyse historique.

2 En effet, comme le rappellent les deux auteurs dans une belle introduction qui retrace, à la manière d'une double ego-histoire, le parcours de cette équipe, les feuilles volantes étaient jusqu'alors une pierre angulaire éclatée entre plusieurs disciplines dont chacune se saisissait d'un fragment : les littéraires s'emparaient du texte en délaissant l'image ; les historiens d'art ne retenaient que celle-ci ; quant aux historiens, ils dédaignaient quelque peu ces sources réduites à la simple fonction ancillaire d'illustration.

3 Le très grand mérite des articles ici réunis de W.H et M.S, tous deux auteurs de beaux livres sur la question, est de reconsidérer ces documents en leur offrant le statut de sources historiques. Les dix-huit articles, publiés entre 1985 et 2002 et classés dans un ordre thématique s'attachent avant tout à recontextualiser ces imprimés en s'intéressant principalement au XVIIe s. et à leur redonner leur valeur de sources historiques en soulignant notamment l'importance capitale de ces feuilles dont l'attention tatillonne et prompte à la censure des autorités politiques à leur égard témoigne. Trois autres études s'intéressent à l'histoire matérielle de la production et de la diffusion de ces feuilles volantes dans le contexte de la guerre de Trente Ans qui donna lieu à une véritable inflation d'imprimés tantôt louangeurs pour ses héros, tels 
Gustave-Adolphe de Suède, tantôt diffamatoires et pour cette raison très vite poursuivis par la justice. Un troisième pôle thématique propose une étude sociale de ces productions qui sont aussi une représentation du monde social : celui des lettrés qui en diffusent en nombre plus restreint et en latin. Plus généralement, les Flugschriften offrent des visions d'un monde en crise. Elles seraient aussi, selon les auteurs, un instrument du processus de civilisation.

4 Enfin, les feuilles volantes comportent une dimension politique indéniable à laquelle huit contributions consacrent de nombreuses pages balayant la période des XVIe et XVIIe s., depuis la fracture religieuse luthérienne et ses feuilles volantes violemment anti-pontificales, jusqu'aux nombreux imprimés publiés pendant la guerre de Trente Ans. Les deux derniers articles qui closent l'ouvrage envisagent un autre aspect des conditions de production de ces œuvres : les villes ainsi que les cercles littéraires pour qui ce média autorise de multiples variations des genres.

5 Ce recueil très utile et soutenu par une très riche bibliographie dresse ainsi un bilan riche et toujours très clair de ce nouveau pan de la recherche, à la confluence entre histoire du livre et de l'imprimé, histoire intellectuelle et politique.

Naïma GHERMANI (Université de Grenoble II) 